\title{
Giant Pyonephrosis Due to Urolithiasis and Diabetes: A Case Report
}

\author{
Alan Hasigov ${ }^{1,2}$, Jean Paul Ndamba Engbang1,2,3*, Felix Fidarov ${ }^{1,2}$ \\ ${ }^{1}$ Republican Clinical Hospital, Vladikavkaz, Russia \\ ${ }^{2}$ North-Ossetian State Medical Academy, Vladikavkaz, Russia \\ ${ }^{3}$ Faculty of Medicine and Pharmaceutical Sciences, The University of Douala, Douala, Cameroon

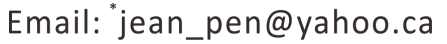

Received 19 May 2016; accepted 11 July 2016; published 14 July 2016

Copyright (C) 2016 by authors and Scientific Research Publishing Inc.

This work is licensed under the Creative Commons Attribution International License (CC BY). http://creativecommons.org/licenses/by/4.0/

(c) ()

\begin{abstract}
Pyonephrosis results from upper urinary tract infection in combination with obstruction and hydronephrosis. The consequence of that is the suppurative destruction of the renal parenchyma. Instead of infection and obstruction which play a role in its etiology, some factors can be considered as risk for pyonephrosis, such as immunosuppression due to medications (steroids), disease (diabetes mellitus, acquired immunodeficiency syndrome [AIDS]). Patients with pyonephrosis may present clinical symptoms and signs such as fever, flank pain and nephromegaly. The diagnose is performed using imaging means (computed tomography, ultrasound). Without treatment, the disease can progress to the urosepsispyonephrosis, which is the most redoubtable complication. The chosen treatment for patients remains nephrostomy or nephrectomy. In some cases, partial nephrectomy may be an option. We are presenting a case of a diabetic patient who with a giant pyonephrosis.
\end{abstract}

\section{Keywords}

Giant Pyonephrosis, Urolithiasis, Diabetes

\section{Introduction}

Pyonephrosis, is a disease base on two factors, urinary tract infection and obstructed kidney. It's a suppurative process of the urinary tract and kidney causing destruction of the renal parenchyma [1]. Some factors exposed patients to the development of pyonephrois; there are immunodepression due to medications (steroids, long term treatment by antibiotics), disease (diabetes mellitus, AIDS) [1] [2]. The most common cause of pyonephrosis is kidney stones, others causes do exist. Depending on the mechanism by which obstruction occurs, the most

"Corresponding author. 
common causes can be divided in two groups: intrinsic obstruction causes (lithiasic ureteral obstruction; partially or totally obstructive kidney stones, etc.), and extrinsic obstruction causes (infiltrative bladder tumours with obstruction or compression of the ureteral orifice, prostatic carcinoma, pregnancy, etc.) [3]-[5]. Multiple infectious agents can be isolated in patients, such as Proteus, E. coli, Enterobacter, Klebsiella pseudomonas [6]. The most commonly symptoms are Fever, chills, and flank pain [1] [2] [6]-[8]. If not recognized and treated promptly, this infectious process may progress, often resulting in clinical deterioration of the patient with urosepsis. The diagnosis is performed by ultrasound (USG), computed tomography (CT), urography, and magnetic resonance imaging (MRI) [1] [6] [7]. Drainage (either percutaneously or retrograde with a ureteral stent) is the mainstay of treatment, but nephrectomy, depending of cases is also used [1] [6]-[8]. We obtained the informed consent from the patient for this study.

\section{Case Presentation}

A 49-year-old female patient presented with right flank pain, nausea, vomiting, fever, general weakness for 2 weeks and developed abdominal distention of 10 days ago. Clinical evaluation of other systems did not reveal any abnormality. Endocrinologist consultation firstly found diabetes mellitus type 2. An abdominal ultrasound revealed a large abdominal mass. Whole abdomen CT found an abnormal right kidney, $234 \times 300 \times 279 \mathrm{~cm}$ in size, with tuberous distinct contours. In the projection of the pyelocaliceal system, CT revealed three stones up to $20 \mathrm{~mm}$. The left kidney was normal $69 \times 94 \times 130 \mathrm{~mm}$ in size, parenchyma up to $27 \mathrm{~mm}$, his Pyelocaliceal system was not expanded (Figure 1).

The patient underwent radical nephrectomy with a diagnosis of nonfunctioning left kidney due to giant pyonephrosis caused by stones (Figure 1).

During the operation, Ten liters of purulent material was drained, and three stones of $1,1.6$ and $2 \mathrm{~cm}$ diameter were removed.

Macroscopically, the material of the nephrectomy had parts of white and brown in color; it was $32 \times 18 \times 7$ $\mathrm{cm}$ in size and $1210 \mathrm{~g}$ in weight, with cystic nodularity as shown in Figure 2. The anatomo-pathology's result was hydronephrosis and chronic pyelonephritis. The germ found was Escherichia coli. E. coli was identified as medium, pink-to-red colonies and was confirmed by positive indole test.

The patient was seen after two and four months, she was noted to be doing well. Utrasonography, computed tomography and laboratory tests did not demonstrate problems in other kidney.

\section{Discussion}

Pyonephrosis is an uncommon disease, the basis of which includes infection and obstruction of the upper urinary tract. Indeed, some immunosuppresives situations can play a supporting role; there may be mentioned ailments including diabetes, acquired immune deficiency syndrome. Our presented case, a giant pyonephrosis with 10 liters of pus confirms the data of the literature. This patient had not only obstructive pyelonephritis, but also a key factor favoring, diabetes type 2 . It is probably this combination of causative factors that makes the particularity

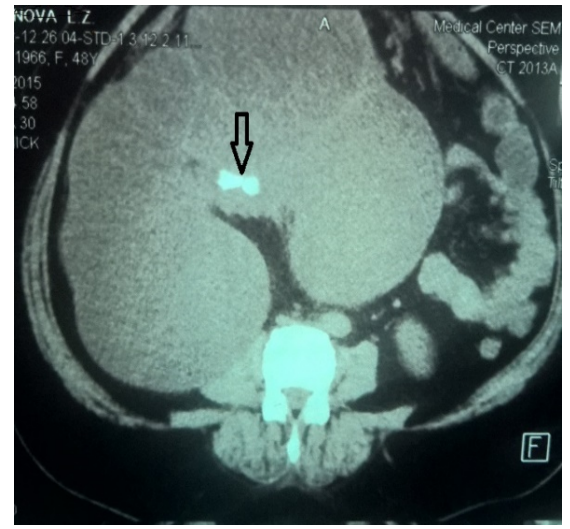

(a)

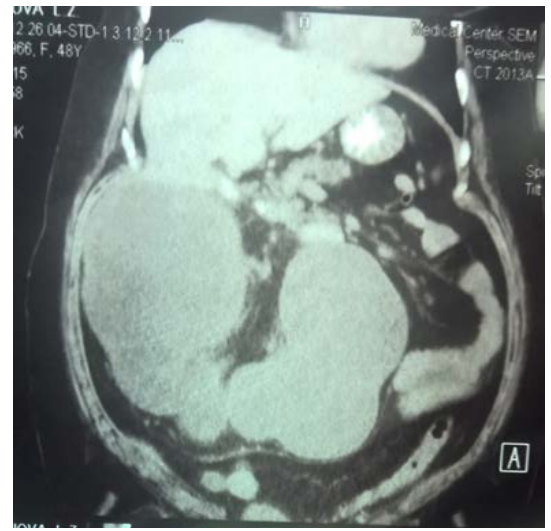

(b)

Figure 1. Abnormal right kidney, with tuberous distinct contours and stones (arrow). 


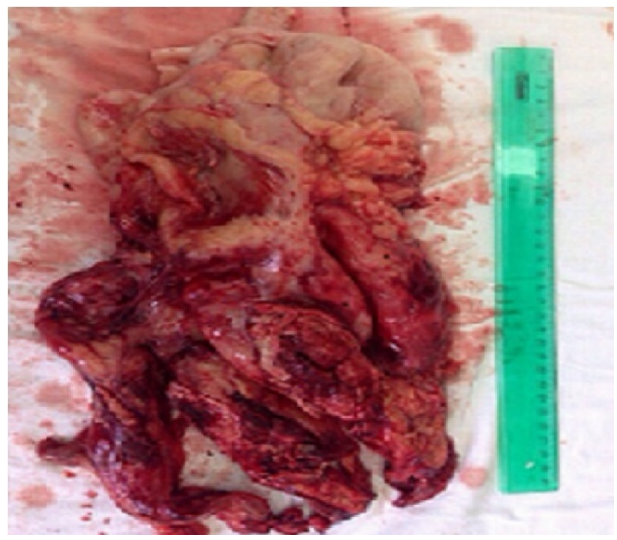

Figure 2. Macroscopic view of the kidney.

of the case, not only in its evolution (less than 2 weeks) but also in its presentation (10 liters), so it's a rare case. Indeed, in the literature, many authors have described cases Pyonephrosis among diabetics [2] [7], pyonephrosis obstructive because even with cases of 7 liters [1] [6] [8], but no cases of combined etiology and of such a volume as in our case.

Clinical signs presented by our patient were flank pains, nausea, vomiting, fever, general weakness. Sow et al. in Senegal, describing 44 cases, found that the most common clinical manifestations were acute flank pain, sepsis and renal mass [7]. The clinical presentation of the patients described by Carneciu et al., was back pain in 84\%, fever and chills are found on $46 \%$ of all patients [1]. For Mohammed, who studied pyonephrosis in 19 cases, clinically, all patients presented with fever, lower back pain and a significant deterioration in general health [8].

Patients with underlying diabetes are of particular concern, as they are more vulnerable to the development of a complication from acute pyelonephritis, including renal abscesses and emphysematous pyelonephritis [9]. Additionally, it is also more difficult to establish the diagnosis on clinical grounds in diabetics, since as many as $50 \%$ will not have the typical flank tenderness that helps to differentiate pyelonephritis from lower urinary tract infection in an otherwise healthy patient [2] [3]. Predisposition to genital infections and urinary tract infections (UTI) in type 2 diabetes mellitus (DM) results from several factors such as glucosuria, adherence of bacteria to the uroepithelium and immune dysfunction. Insights were obtained in the association between sodium-glucose cotransporter-2 (SGLT2) inhibitors, as medication for diabetes mellitus type 2, and a small increased risk for UTI due to glucosuria and the possible negative effects of UTI, including urosepsis, on bladder and kidney function in diabetic women [10].

Our diagnostic was based on utrasonography and computed tomography. Many authors confirmed the interest and even the indispensability of ultrasound and CT in the diagnosis of pyonephrosis [1] [3] [6]-[8] [11]. The sensitivity of renal ultrasonography for differentiating hydronephrosis from pyonephrosis is $90 \%$, and the specificity is $97 \%$ [11]. CT better specify the nature of the obstruction, renal function, severity of the infringement and the perirenal inflammation that takes the form of a simple thickening of the fascia, a perirenal abscess collected or not. The CT scanning helps to do the differential diagnosis, because it shows definitive delineation of the obstruction, the function of the kidney, and the severity of hydronephrosis, as well as the presence of other abdominal pathologies, including metastatic cancer, retroperitoneal fibrosis, and renal stones that are not visible on the sonogram [1] [3].

Although Eco-guided percutaneous nephrostomy is considered like the first intention in the surgical treatment of pyonephrosis to reduce the degree of kidney expansion by draining the pus from renal cavities, and to reduce the degree of secondary perinephritis, Nephrectomy is the surgical treatment of choice if contralateral kidney is healthy [1]. In our case, the nephrectomy was indicated considering the fact that the contralateral kidney was healthy and the left side was unfunctionned due of stones.

E. coli was the germ isolated in the pus of our patient. Patients with Diabetes Mellitus have a higher incidence of symptomatic UTI, which more often lead to complications compared with those without diabetes. Therefore these UTI are generally considered as complicated UTI [9]. The increased adherence of bacteria to uroepithelial cells has been observed in patients with diabetes, particularly E. coli expressing type-1 fimbriae [12]. Adherence 
of $E$. coli with type 1 fimbriae to uroepithelial cells is higher in patients with poor glycaemia control [9] [10].

\section{Conclusion}

The coexistence of urolithiasis and diabetes mellitus in a patient may complicate a pyelonephritis and cause pyonephrosis with gigantic size. In this case, which generally leads to the non-functionality of the affected kidney, nephrectomy remains the indicated treatment.

\section{References}

[1] Scarneciu, I., Constantina, A., Grigorescu, D. and Maxim, L. (2015) Pyonephrosis: Diagnosis and Treatment: Report of 65 Cases. Journal of Molecular Biology, 2, 122-125.

[2] Taheri, A.A., El Aziz, S. and Chadli, A. (2015) Acute Pyelonephritis in Diabetic Patients. Annales d'Endocrinologie, 76, 558. http://dx.doi.org/10.1016/j.ando.2015.07.875

[3] Schaeffer, A.J. and Schaeffer, E.M. (2007) Infections of the Urinary Tract. In: Wein, A.J. and Kavoussi, L.R., Eds., Campbell-Walsh Urology, 9th Edition, Saunders Elsevier, Philadelphia.

[4] Chung, S.D., Lai, M.K., Chueh, S.C., Wang, S.M. and Yu, H.J. (2009) An Unusual Cause of Pyonephrosis and IntraPeritoneal Abscess: Ureteral Urothelial Carcinoma. International Journal of Infectious Diseases, 13, e39-e40. http://dx.doi.org/10.1016/j.ijid.2008.06.038

[5] Bal, A., Aulakh, R., Mohan, H. and Bawa, A.S. (2007) Mucinous Adenocarcinoma of the Renal Pelvis Presenting as Pyonephrosis: A Case Report. Indian Journal of Pathology and Microbiology, 50, 336-337.

[6] Erol, A., Çoban, S. and Tekin, A. (2014) A Giant Case of Pyonephrosis Resulting from Nephrolithiasis. Case Reports in Urology, 3, 161640. http://dx.doi.org/10.1155/2014/161640

[7] Sow, Y., Fall, B., Sarr, A., Thiam, A., Diao, B., Fall, P.A., et al. (2011) Pyonephrosis: 44 Cases in Senegal. Médecinetropicale, 71, 495-498.

[8] Mohamed, A. and Mohammed, R. (2012) Management of Pyonephrosis: Our Experience. Webmed Central Urology, 3, WMC003420

[9] Geerlings, S.E. (2008) Urinary Tract Infections in Patients with Diabetes Mellitus: Epidemiology, Pathogenesis and Treatment. International Journal of Antimicrobial Agents, 31, S54-S57. http://dx.doi.org/10.1016/j.ijantimicag.2007.07.042

[10] Geerlings, S.E., Fonseca, V., Castro-Diaz, D., List, J. and Parikh, S. (2014) Genital and Urinary Tract Infections in Diabetes: Impact of Pharmacologically-Induced Glucosuria. Diabetes Research and Clinical Practice, 103, 373-381. http://dx.doi.org/10.1016/j.diabres.2013.12.052

[11] van Nieuwkoop, C., Hoppe, B.P., Bonten, T.N., Van’tWout, J.W., Aarts, N.J., Mertens, B.J., et al. (2010) Predicting the Need for Radiologic Imaging in Adults with Febrile Urinary Tract Infection. Clinical Infectious Diseases, 51, 1266-1272. http://dx.doi.org/10.1086/657071

[12] Geerlings, S.E., Meiland, R., van Lith, E.C., Brouwer, E.C., Gaastra, W. and Hoepelman, A.I. (2002) Adherence of Type 1-Fimbriated Escherichia coli to Uroepithelial Cells: More in Diabetic Women than in Control Subjects. Diabetes Care, 25, 1405-1409. http://dx.doi.org/10.2337/diacare.25.8.1405 


\section{Submit or recommend next manuscript to SCIRP and we will provide best service for you:}

Accepting pre-submission inquiries through Email, Facebook, LinkedIn, Twitter, etc.

A wide selection of journals (inclusive of 9 subjects, more than 200 journals)

Providing 24-hour high-quality service

User-friendly online submission system

Fair and swift peer-review system

Efficient typesetting and proofreading procedure

Display of the result of downloads and visits, as well as the number of cited articles

Maximum dissemination of your research work

Submit your manuscript at: http://papersubmission.scirp.org/ 